\title{
A Large Dentigerous Cyst Obliterating the Maxillary Sinus Leading to Nasal Obstruction and Impaired Hearing: A Case Report
}

\author{
Dr. Naveen Kumar Muniganti ${ }^{1 *}$, Dr. Sathyakumar Reddy ${ }^{2}$, Dr. Rajasekhar Gali.G ${ }^{3}$, Dr. Ramesh Babu Vaka ${ }^{4}$, Dr. Ramani ${ }^{5}$
}

${ }^{1}$ Post Graduate, ${ }^{2}$ Professor and Hod, ${ }^{3,4}$ Professor, ${ }^{5}$ Senior Lecturer, Department of Oral and Maxillofacial Surgery, Narayana Dental College and Hospital, Chinthareddypalem, Nellore- 524002, Andhra Pradesh, India

DOI: $10.36347 /$ simcr.2020.v08i04.008

| Received: 26.03.2020 | Accepted: 02.04.2020 | Published: 08.04.2020

*Corresponding author: Dr. Naveen Kumar Muniganti

\section{Abstract}

Dentigerous cyst is the most commonly occurring odontogenic cyst after a radicular cyst and accounts for $15 \%$ of all true cysts in the jaws. The cyst is more common in mandible than in the maxilla. The dentigerous cyst is commonly associated with impacted mandibular third molars. In the maxilla, the incidence is rare. Dentigerous cyst in the maxillary sinus in association with an impacted third molar is an uncommon entity. We present a case of dentigerous cyst associated with an impacted third molar, obliterating the maxillary sinus leading to nasal obstruction and impaired hearing in a 37-year-old male.

Keywords: Dentigerous cyst, impacted third molar, maxillary sinus, impaired hearing, nasal obstruction. Copyright @ 2020: This is an open-access article distributed under the terms of the Creative Commons Attribution license which permits unrestricted use, distribution, and reproduction in any medium for non-commercial use (NonCommercial, or CC-BY-NC) provided the original author and source are credited.

\section{INTRODUCTION}

Dentigerous cyst accounts for $15 \%$ of all true cysts in the jaws and is the second most commonly occurring odontogenic cyst after radicular cyst. It is thought to arise from the remnants of enamel organ after the enamel formation has been completed [1]. About $70 \%$ of the dentigerous cysts occur in the mandible and $30 \%$ in the maxilla [2]. The dentigerous cyst is commonly associated with impacted mandibular third molars. The incidence of its occurrence in the maxilla is rare, and in such a case, it is usually seen associated with an impacted canine. Still, its association with an impacted third molar is very rare. It is commonly seen in the age group of 18 and 25 years when third molars are supposed to erupt.

Moreover, dentigerous cyst in the maxillary sinus in association with an impacted third molar is an uncommon entity; and the failure to intervene may cause impingement on the nasal septum, orbit, alveolar arch, and hard palate [3]. Some of the untreated dentigerous cysts have the potential to develop odontogenic tumors like ameloblastoma, and also into malignancies like oral squamous cell carcinoma and mucoepidermoid carcinoma $[4,5]$.

\section{Case Report}

A 37-year-old male was referred to the Department of Oral and Maxillofacial Surgery from the
ENT department. The patient consulted ENT specialist for his complaint of nasal obstruction and some impaired hearing with his right side face region. They did nasal endoscopy and CT PNS view and found some cystic pathology arising from the dental origin, which made them refer the patient to the OMFS department. On examination, the patient presented with mild facial asymmetry due to swelling on the right side of the face [Figure 1]. The patient gave a history of recurrent sinusitis and headache. Intraoral examination revealed missing third molars; CT scan showed a tooth in the right maxillary sinus; the coronal CT image showed a lesion inducing near-complete opacity of the maxillary sinus [Figure 2a, 2b]. The initial diagnosis of the dentigerous cyst was made provisionally on clinical and radiographic findings. Incisional biopsy was done under local anesthesia, and its histopathological analysis suggested the lesion as a dentigerous cyst. Complete enucleation of the cyst along with the impacted third molar was done by intraoral approach under general anesthesia, by exposing the anterolateral wall of the maxillary sinus [Figures $3 \mathrm{a}$ and $3 \mathrm{~b}$ ], and the closure was done by resorbable suture material. The specimen was sent for the histopathologic examination, which confirmed the diagnosis as a dentigerous cyst. The patient was kept on regular follow-up for 18 months when there were no signs of recurrence and also with improved nasal patency with enhanced hearing. 


\section{Case photographs}

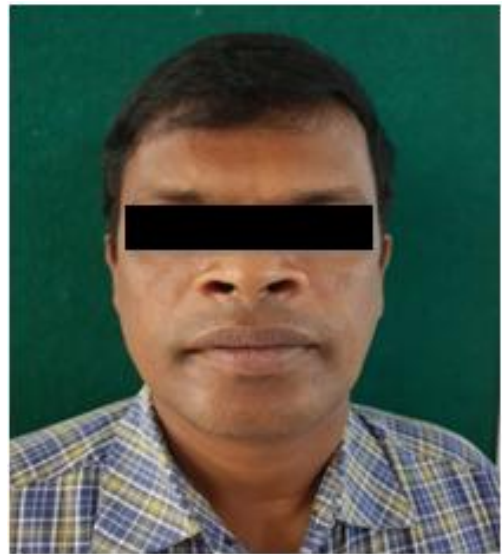

Fig-1: very mild swelling noticed over his right side cheek region
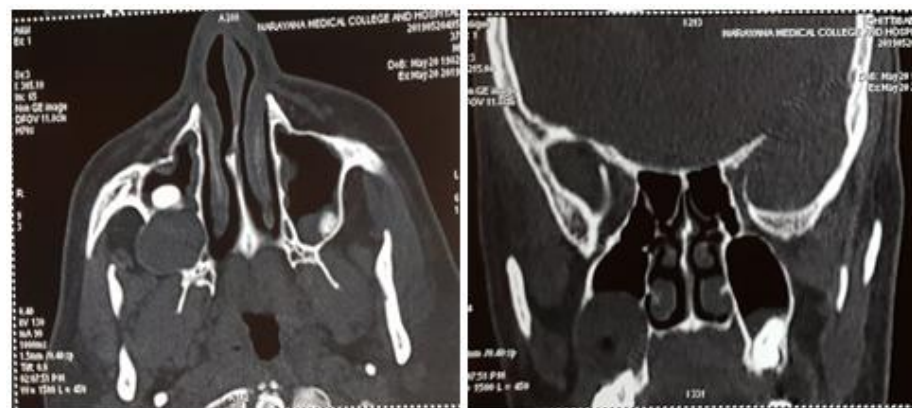

Fig-2a and 2b: CT PNS scan (axial and coronal sections) view showing impacted the third molar surrounded by radiolucency in the right maxillary sinus

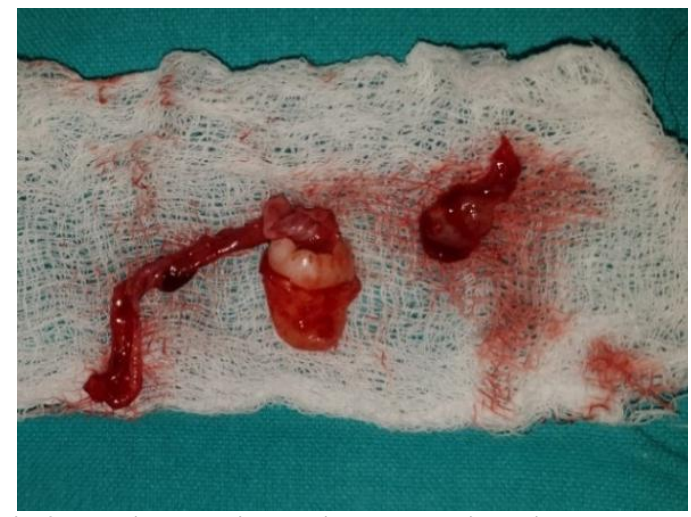

Fig-3a: Excised specimen with the associated impacted tooth

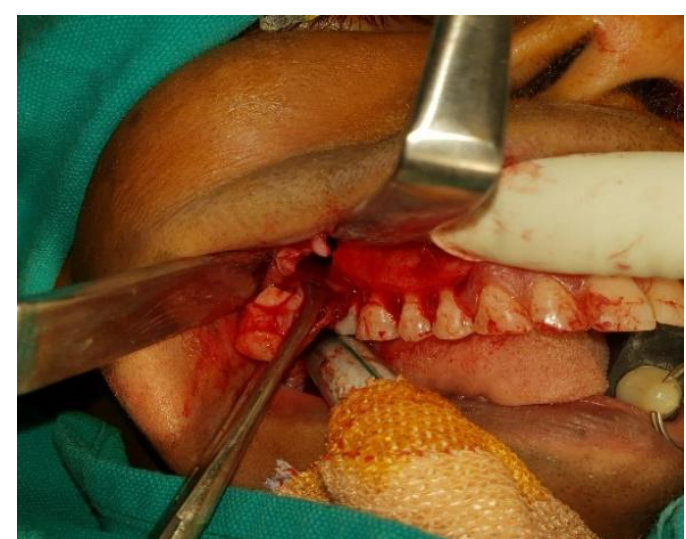

Fig-3b: Enucleation of the cyst by an intraoral approach

\section{DisCUSSION}

Dentigerous cysts are the second most common benign developmental odontogenic cyst after radicular cyst. The meaning dentigerous is "toothbearing" and is coined by Paget in 1853. The majority of dentigerous cyst is seen associated with the mandibular $3^{\text {rd }}$ molars, and the order of its occurrence is MANDIBULAR $3^{\text {RD }}$ MOLARS >MAXILLARY PERMANENT CANINES $>$ MANDIBULAR PREMOLARSS $>$ MAXILLARY $3^{\text {RD }}$ MOLARS. Eliasson et al. reported a $1 \%$ occurrence of these cysts in an impacted upper 3M tooth [6]. Dentigerous cyst associated with an ectopically erupted tooth within the maxillary sinus is a sporadic occurrence.

Our patient presented with a complaint of nasal obstruction and impaired hearing associated with mild swelling of his right side cheek region. His CT paranasal sinus view revealed a well-defined expansile cystic lesion measuring $2.7 \times 2.4 \times 2.5 \mathrm{cms}$ in size with peripheral interrupted calcification; it is seen arising from the crown of an unerupted 18 tooth. Superiorly the cyst extends into the cavity of the right maxillary sinus with the erosion of maxillary antrum. Posterolaterally, the cyst appears to be eroding the right maxillary wall with exophytic extension into the masticatory space. The sino -nasal tract and the ears are practically connected through the Eustachian tubes located in the nasopharynx. Nose and sinus congestion and stuffiness, 
as well as postnasal drip, may therefore affect the pressure in the middle ear [7]. The sinus obliteration with this odontogenic cyst might result in dysregulation of acoustic balance there by resulting in impaired hearing. The unerupted tooth is seen to be displaced anteriorly and superiorly into the right max. Sinus [Figure: 2a, 2b].

If not treated, early cyst in the maxillary sinus may displace and obliterate the maxillary antrum and nasal cavity. Further, the cyst may cause pathological fracture and may become secondarily infected [8]. Metastatic and dysplastic changes, associated aneurismal bone cyst, and hemangiomas have also been reported in rare instances [8]. Ectopic eruption of a tooth into the dental environment is common, whereas ectopic eruption of a tooth in other sites is rare. Its presence in the maxillary sinus is a rare entity, and very few cases have been reported in the literature [9]. The ectopic eruption may result due to one of the three processes: Developmental disturbances, pathological process, and iatrogenic activity [9]. It is believed that the displacement of the tooth buds by the expansion of these dental cysts results in the displacement of the tooth to other areas, as was seen in our case.

Dentigerous cysts are usually single lesions. But bilateral and multiple cysts have been reported in patients with syndromes such as mucopolysaccharidosis, basal cell nevus syndrome, and cleidocranial dysplasia $[10,11]$. Also, cases of multiple dentigerous cysts involving maxilla and mandible have been reported in the literature [11]. In our case, a small radiolucent lesion often similar to dentigerous cyst is noticed in relation to 28 , and however, it kept on observation on patients' routine follow up visits.

The management of this lesion depends on the age of the patient, site, and extension of the cyst. Various treatment modalities have been proposed. The primary surgical procedure includes marsupialization or enucleation. The modified procedures include a combination of both, use of Carnoy's solution following enucleation and the use of bone grafts to fill the cystic cavity. The recurrence rate of dentigerous cyst is very low as when compared to other jaw cysts [11].

In the present case, enucleation was preferred over the marsupialization. Since there was no danger of devitalizing teeth, the surgical procedure did not require any sacrifice of any vital structure, and the impacted third molar was nonfunctional.

\section{CONCLUSION}

This case report highlights the unerupted maxillary third molar being displaced into the maxillary sinus by its association with an expanding dentigerous cyst, which was almost completely obliterating the maxillary sinus, thereby leading to nasal obstruction and impaired hearing. Very few such cases have been reported in the literature. Since the untreated cyst may lead to facial asymmetry, infection, nasal obstruction, and even metaplastic and dysplastic changes, its diagnosis and treatment are essential.

\section{REFERENCES}

1. Das SK, Bhowmick A, Mukherjee S, Ghosh LM, Banerjee S. Giant Dentigerous Cyst. Int J Head Neck Surg. 1999; 51:3.

2. Bhaskar SN. Synopsis of oral pathology. 7th ed. New Delhi: CBS Publisher; 1986: 228-37.

3. Isser DK, Das S. Dentigerous cyst arising in young Indian boy. J Otolaryngol Head Neck Surg. 2002; 54:44-5.

4. Slotweg PJ. Carcinoma arising from reduced enamel epithelium. J Oral Pathol.1987;16:479-82.

5. Yasouka T, Yonemoto K, Kato Y, Tatematsu N. Squamous cell carcinoma arising in a dentigerous cyst. J Oral Maxillofac Surg. 2000;58:900-5.

6. Eliasson S, Heimdahl A. Nordenram: Pathological changes related to long- term impaction of third molars. A radiographic study. Int. J. Oral Maxillofac. Surg. 1989; 18: 210-212.

7. Low WK and Willatt DJ. The relationship between middle ear pressure and deviated nasal septum. Clinical otolaryngology and allied sciences.1993; 18: $308-10$.

8. Ustuner E, Fitoz S, Atasoy C, Erden I, Akyar S. Bilateral maxillary dentigerous cysts: A case report. Oral Surg Oral Med Oral Pathol OralRadiolEndod.2003; 95:632-5.

9. Bodner L, Tovi F, Bar-Ziv J. Teeth in maxillary sinus: Imaging and management. J LaryngolOtol.1997; 111:820-4.

10. Robert MW, Barton NW, Constantopoulos G, Butler DP, Donahue AH. Occurrence of multiple dentigerous cysts in a patient with the MorateaxLamy syndrome (mucopolysaccharidosis, type VI). Oral Surg Oral Med Oral Pathol. 1984; 58:169-75.

11. Norris L, Piccoli P, Papageorge MB. Multiple dentigerous cysts of maxilla and mandible report of a case. J Oral Maxillofac Surg. 1987; 45:694-7. 